\title{
APLIKASI PENDIDIKAN LINGKUNGAN HIDUP BAGI ANAK TINGKAT SEKOLAH DASAR DALAM MEMBENTUK KEPEDULIAN ANAK TERHADAP LINGKUNGAN (Studi Kelembagaan NGO OISCA Pati)
}

Hidayatussholihah

Dosen FAI UNISSULA Semarang

Email: hida@unissula.ac.id

\section{Lum'atun Nadzifah}

Peneliti Kelembagaan NGO OISCA Pati

Email: lumatunnadzifah@gmail.com

\begin{abstract}
Children's Forest Program is education program for live environmentally through sound involve primary school children in five school at the Pati regency. In order to provide generation who are care about long lasting nature OISCA as Institution on a self supporting community like support material education environment in CFP program than collaboration with primary school in the Pati regency. This research intent on detect implementation and implication Children's Forest Program at the mitra school OISCA Pati toward enhancement factor children care in the school area with applying for field research as reference to have data and description about OISCA Pati contribute in the made way for young generation to care concerning about conservation live environmentally. With this research extend expectable to new input at all parties which plunge into an activity in the program education environment in a general manner and particularry OISCA Pati as location have been this researched.
\end{abstract}

Keywords: Implementation Study, Implication, CFP OISCA Pati.

\section{Abstrak}

Children's Forest Program merupakan program pendidikan lingkungan hidup melalui penghijauan yang melibatkan anak-anak sekolah tingkat dasar di lima sekolah di Kabupaten Pati. Dalam rangka menyiapkan generasi yang peduli terbadap kelestarian alam OISCA sebagai Lembaga Swadaya Masyarakat memfasilitasi materi pendidikan lingkungan dalam program CFP yang kemudian bekerjasama dengan sekolah dasar di Kabupaten Pati. Penelitian ini bertujuan untuk mengetabui 
implementasi dan implikasi Children's Forest Program di sekolah mitra OISCA Pati terhadap peningkatan kepedulian anak di lingkungan sekolah dengan menggunakan penelitian lapangan sebagai acuan untuk mendapatkan data dan gambaran tentang peran OISCA Pati dalam menyiapkan generasi muda untuk sadar terbadap pelestarian lingkungan bidup. Dengan penelitian ini diharapkan dapat memberikan masukan baru kepada semua pibak yang berkecimpung di bidang pendidikan lingkungan bidup pada umumnya dan khususnya OISCA Pati sendiri sebagai tempat dilakukannya penelitian ini.

Kata kunci: Kajian Implementasi, Implikasi, CFP OISCA Pati.

\section{A. Pendahuluan}

Sesuai data FAO, badan dunia yang menangani masalah pangan dan pertanian, laju penghancuran hutan di Indonesia pada tahun 2000-2005 merupakan yang tercepat di dunia. Setiap tahun rata-rata 1,871 juta hektar hutan hancur, atau dua persen dari luas hutan yang tersisa 88,495 juta pada tahun 2005. itulah sebabnya maka Indonesia berhak menyandang rekor Guinness World Record, untuk mencatat Indonesia sebagai negara penghancur hutan tercepat 2008. Indonesia menghancurkan hutan seluas 300 lapangan sepak bola setiap jamnya. Di Indonesia saat ini diperkirakan $72 \%$ hutan asli telah musnah. Setengah dari luas hutan yang tersisa sekarang pun terancam penebangan untuk komersial, kebakaran hutan, dan pembukaan hutan untuk lahan kebun sawit. ${ }^{1}$

Perilaku manusia pun berkembang dari yang sebelumnya mencintai, dan menghargai alam menjadi cenderung mengeksploitasi alam. ${ }^{2}$ Manusia modern (manusia yang menjadikan akal, ilmu dan teknologi sebagai acuan utama dalam kehidupan) telah menciptakan banyak kesenjangan antara sumber daya dengan jumlah penduduk suatu wilayah atau daerah. ${ }^{3}$ Dengan banyaknya penduduk di muka bumi, semakin banyak pula perbuatan-perbuatan manusia tidak memiliki sikap kepedulian lingkungan.

Munculnya permasalahan alam di Indonesia, seperti Fenomena global warming akibat kasus kebakaran hutan yang terjadi di Kalimantan, kebakaran hutan tersebut telah menimbulkan dampak yang luar biasa, ratusan orang tewas dan jutaan orang terserang

${ }^{1}$ Devisi CFP Pusat, Pedoman CFP (Cildren's Forest Program) ,1993, hlm. 1

${ }^{2}$ Quraisy Shihab, Tafsir Al-misbah, pesan, kesan dan keserasian Al-Qur'an, volume 5 (Jakarta: Lentera hati, 2004), hlm. 272.

${ }^{3}$ Mattulada, Lingkungan Hidup Manusia, (Jakarta: Pustaka Sinar Harapan, 1994), hlm.72. 
infeksi saluran pernapasan akut (ISPA) akibat asap kebakaran tersebut. ${ }^{4}$ Selain itu tingginya konsentrasi gas rumah kaca akibat tingginya kandungan CFC (gas metana dan klorofluoro karbon) di atmosfer dapat merusak lapisan ozon, kemusnahan berbagai spesies flora dan fauna, serta erosi. Banjir akibat pola hidup manusia yang membuang sampah sembarangan di aliran sungai, tanah longsor akibat penebangan pohon yang digunakan sebagai lahan pertanian maupun perumahan. ${ }^{5}$

Beberapa hal tersebut merupakan akibat dari ulah tangan manusia sendiri yang tidak peduli dengan lingkungan. Sementara itu rasa ketidak pedulian terhadap lingkungan sekarang ini mulai banyak tercermin pada perilaku peserta didik. Fenomena tidak peduli lingkungan ditampilkan pada perilaku sehari-hari. Sebagian besar dari peserta didik tidak mampu menghubungkan antara apa yang mereka pelajari dengan bagaimana pengetahuan tersebut digunakan. Seperti peserta didik mengetahui materi pencemaran lingkungan tetapi mereka masih membuang sampah tidak pada tempatnya, membiarkan lingkungan yang kotor dengan sampah, membiarkan tanaman rusak dan tidak merawatnya. ${ }^{6}$

Syariat diturunkan untuk menjaga lima pokok kemaslahatan yaitu: agama, jiwa, keturunan, harta dan akal. Berdasarkan pendapat Asy-Syatibi, "Sesungguhnya lima hal pokok diatas merupakan keharusan untuk menegakkan kemaslahatan-kemaslahatan agama dan dunia, di mana kalau prinsip-prinsip ini ditinggalkan maka kemaslahatan dunia tidak akan dapat berdiri dengan tegak, sehingga mengakibatkan kerusakan dan hilangnya kenikmatan, yang berakibat penyesalan-penyesalan abadi." ${ }^{, 7}$ Maka apabila di cermati, tidak diragukan lagi bahwa pemeliharaan terhadap lingkungan, pelestarian dan pengembangannya tercakup dalam kategori lima maslahat pokok.

${ }^{4}$ Nyoto Santoso, "kebakaran hutan gambut dan global warming, 2015", http:// nasional.sindonews.com, diakses pada 21 Desember 2016.

5 Tholhah dan Ahmad Mufid, Fiqib Ekologi: Menjaga Bumi Memahami Makna Kitab Suci, (Yogyakarta : Total Media, 2008), hlm. 60.

${ }^{6}$ Frismi astuti, "Implementasi Program Adiwiyata Dalam Pengelolaan Lingkungan Sekolah dan Tingkat Partisipasi Warga Sekolah di SMP Kabupaten Wonosobo" Tahun 2015. vol. xix no. 2 (November 2014), http://journal.unnses.ac.id/sju/index.php/edugeo, di akses tanggal 21 Desember 2016.

${ }^{7}$ Yusuf Al-Qaradhawi, Islam Agama Ramah Lingkungan, (Jakarta Timur: Pustaka Al-Kautsar, 2002), $h \operatorname{lm} 63$. 
Segala usaha pemeliharaan lingkungan sama halnya dengan usaha menjaga agama. Maka dari itu, menjaga lingkungan termasuk kategori mendasar. Karena memang, perbuatan dosa yang dapat mencemari lingkungan akan menodai substansi dan keberagaman yang benar, dan secara tidak langsung meniadakan tujuan eksistensi manusia dipermukaan bumi ini. Sekaligus juga menyimpang dari perintah Allah dalam konteks hubungan baiknya dengan sesama. ${ }^{8}$

Salah satu konsep pemeliharaan lingkungan dalam Islam adalah perhatian akan penghijauan dengan cara menanam dan bertani berdasarkan pendapat Asy-syatibi. ${ }^{9}$ Maka penulis sepakat bahwa upaya penghijauan ini berdasar pada manfaat dan juga keindahan, salah satu manfaat penghijauan untuk manusia berupa makan-makanan yang dimakan oleh manusia selain itu penghijauan digunakan sebagai media pendidikan anak sebagai upaya pelestarian lingkungan hidup.

OISCA International (The Organization for Industrial Spiritual and Cultural Advancement International) sebagai Lembaga Swadaya Masyarakat berkontribusi terhadap pembangunan berkelanjutan yang ramah lingkungan Humanity melalui pendekatan holistik yang menekankan keterkaitan pertanian, integritas ekologi, dan jiwa manusia. Untuk mencapai hal ini, OISCA Internasional mengimplementasikan dan pendukung tangan-program experiential bagi warga dunia dari segala usia, transmisi pengetahuan dan keterampilan, dan budidaya kualitas spiritual sebagai dedikasi, kemandirian, dan universal saudarapersaudaraan..$^{10}$

Dalam perayaan ulang tahun ke-30, yakni pada tahun 1991 OISCA menyelenggarakan sebuah konvensi di Fukuoka, Jepang, dengan tujuan mendorong 18.000 peserta untuk "Pikirkan tentang Ibu Bumi." Pada hari yang sama, OISCA resmi meluncurkan Program Forest Anak-anak.$^{11}$ Program ini bertujuan untuk mendidik anak-

\footnotetext{
${ }^{8}$ Yusuf Al-Qaradhawi, Islam..., hlm. 64.

${ }^{9}$ Yusuf Al-Qaradhawi, Islam..., hlm. 81.

10 “mission”, http://www.oisca-international.org, diaskes tanggal 4 Januari 2017 .

11 “milestones”, http://www.oisca-international.org, diaskes tanggal 5 Januari 2017.
} 
anak sekolah dan masyarakat tentang lingkungan melalui tangan-on penanaman pohon dan kegiatan lingkungan terkait lainnya. ${ }^{12}$

Pendidikan lingkungan yang digagas oleh OISCA bertujuan agar anak-anak sedini mungkin dapat mencintai, melindungi, memelihara tanaman dan lingkungannya, maka program ini disebut "Program Hutan Anak Anak" atau yang disebut juga dengan "Children's Forest Program “.

Bentuk kegiatan konkretnya adalah melaksanakan kegiatan penyuluhan, nature game serta kegiatan yang mengarah kepada kecintaaan anak-anak kepada lingkungan. Sebagai media belajar juga melaksanakan penghijauan/penanaman pohon dengan melibatkan anak-anak tingkat sekolah dasar dan menengah. Upaya yang telah dilakukan untuk mengembangkan program ini adalah menjalin kerjasama dengan para alumni OISCA/LSM, pemerintah dan masyarakat setempat. Dengan motto "Lindungi Hutan dan Bumi Kita Bersama Anak-Anak” program ini mengajak kepada seluruh lapisan masyarakat pada umumnya dan dunia pendidikan serta anak-anak pada khususnya, untuk tetap peduli pada hutan dan lingkungan di Bumi ini, guna menciptakan generasi baru yang sangat peduli akan kelestarian lingkungannya. ${ }^{13}$

Mengingat pentingnya pelestarian lingkungan, Jaringan OISCA Pati yang tegabung dalam himpunan alumni OISCA Indonesia bertanggung jawab atas daerahnya untuk melaksanakan Children's Forest Program (CFP) di beberapa Sekolah dasar sebagai media pengenalan pendidikan lingkungan sedini mungkin, Dengan maksud menyiapkan peserta didik dalam pengembangan diri untuk membangun kesadaran agar peduli terhadap lingkungan.

Children's Forest Program mulai masuk di sekolah dasar daerah Pati pada tahun 2013 yakni di SDN Karaban dan SDN Tlogoayu Gabus Pati. ${ }^{14}$ Pendidikan lingkungan hidup memberikan sumbangan besar dalam mengembangkan peserta didik untuk berpikir kritis, memiliki keterampilan pemecahan masalah (problem-solving), keterampilan membuat

\footnotetext{
12 "Programs", http://www.oisca-international.org, diaskes tanggal 4 Januari 2017.

${ }^{13}$ Pedoman CFP (children forest program), hlm. 12.

${ }^{14}$ Wawancara Langsung, Totok Hadi Lukito, Koordinator CFP OISCA PATI, di Margorejo Pati
} pada 2 Desember 2016, 13.20- 14.20 WIB. 
keputusan yang efektif, dan membelajarkan peserta didik agar dapat merespon berbagai isu lingkungan untuk membuat keputusan yang bertanggung jawab.

Pendidikan lingkungan dengan wajah Children's Forest Program yang masuk di lingkup sekolah dasar di Pati yang di bawa oleh NGO OISCA Pati menjadi menarik untuk diteliti, sebab selain jangka pendeknya memberikan warna di dunia pendidikan, jangka panjangnya merupakan sebuah upaya untuk menanamkan kesadaran anak untuk peduli terhadap lingkungan. Maka dari itu peneliti tergerak untuk meneliti tentang "Aplikasi Pendidikan Lingkungan Hidup Bagi Anak Tingkat Sekolah Dasar Dalam membentuk Kepedulian Terhadap Lingkungan Studi Kelembagaan NGO OISCA Pati ", selain itu dalam prakteknya CFP menginternalisasikan nilai kepedulian terhadap lingkungan dan menyiapkan anak sedini mungkin untuk sadar akan hal pelestarian lingkungan.

\section{B. KAJIAN TENTANG IMPLEMENTASI DAN IMPLIKASI CHILDERN'S FOREST PROGRAM}

\section{a. Implementasi Children Forest Program}

CFP (Children's Forest Program) adalah program pendidikan lingkungan hidup bagi anak-anak sekolah dasar dan menengah yang bertujuan agar anak-anak sedini mungkin dapat mencintai, melindungi, memelihara tanaman dan lingkungannya, maka program ini disebut Program Hutan Anak-Anak atau yang disebut juga dengan Children's Forest Program.

Bentuk kegiatan kongkritnya adalah melaksanakan kegiatan penyuluhan, nature game serta kegiatan yang mengarah kepada kecintaaan anak-anak kepada lingkungan. Sebagai media belajar program CFP juga melaksanakan penghijauan/penanaman pohon dengan melibatkan anak-anak tingkat sekolah dasar dan menengah. Upaya yang telah dilakukan untuk mengembangkan program ini adalah menjalin kerjasama dengan para alumni OISC $A$ /LSM, pemerintah dan masyarakat setempat. ${ }^{15}$

Dengan motto Lindungi Hutan dan Bumi Kita bersama Anak-Anak. Program ini mengajak kepada seluruh lapisan masyarakat pada umumnya dan dunia pendidikan serta anak-anak pada khususnya, untuk tetap peduli pada hutan dan lingkungan di Bumi ini, guna menciptakan generasi baru yang sangat peduli akan kelestarian lingkungannya.

\footnotetext{
${ }^{15}$ Panduan CFP, hlm 10
} 
Children Forest Program bertujuan untuk menumbuhkan kesadaran dan cinta terhadap lingkungan sejak usia dini sehingga anak berusaha melindungi dan memelihara tanaman yang ada dimuka bumi ini. ${ }^{16}$

Dalam merintis program ini jaringan NGO OISCA Pati mengambil langkah dengan mencari sekolahan di Pati yang bisa diajak bekerjasama dalam Children Forest Program, berdasarkan penuturan Bapak Totok Hadi Lukito pada saat peneliti temui di rumahnya.

Dari hasil wawancara langsung dengan koordinator CFP dan observasi langsung yang peneliti lakukan dilima SDN mitra OISCA Pati, dalam pelaksanaan program ada kesamaan dengan model konseptual pendidikan lingkungan hidup berbasis partisipasi masyarakat dari hasil analisis terhadap temuan empiris tentang kondisi objektif dilapangan yaitu karakteristik dan kondisi aktual penyelenggaraan pendidikan lingkungan hidup (PLH) di lingkungan lembaga masyarakat Desa Hutan $(\mathrm{LMDH})$ di wilayah eks karisidenan pati oleh Abdul Karim ${ }^{17}$, adapun desain model dalam kajian ini direncanakan terdiri atas beberapa komponen yaitu: (1) landasan model manajemen pendidikan lingkungan hidup, (2) perencanaan pendidikan lingkungan hidup, ruang lingkup materi pendidikan lingkungan hidup, metode dan media pendidikan, evaluasi pendidikan, (3) kegiatan pembelajaran pendidikan lingkungan hidup yang terdiri dari: tujuan pembelajaran, materi pembelajaran, proses pelaksanaan pembelajaran, media dan alat bantu pembelajaran, penilaian, (4) evaluasi pelaksanaan pendidikan lingkungan hidup yang terdiri dari : kriteria keberhasilan dan penyusunan tindak lanjut. ${ }^{18}$

Dalam kajian ini, peneliti menemukan bagaimana perencanaan yang dilakukan oleh OISCA Pati melalui beberapa tahapan yakni identifikasi kebutuhan, perumusan tujuan dan penyusunan program. Dalam pelaknaan program koordinator OISCA Pati memperhatikan pelaksanaan pembelajaran dan pembianaan partisipasi, sedangkan ditahap evaluasi diperhatikan dari mulai kesesuaian program, proses sampai hasilnya dari tahun ke tahun.

1616 Siti Sulikah dkk, Laporan Kelompok KKL 1 PMI IPMAFA di jaringan NGO OISCA Pati, 2015, hlm. 39

${ }^{17}$ Abdul Karim "Manajemen Pendidikan Lingkungan Hidup Berbasis Partisipasi”

${ }^{18}$ Abdul Karim, Manajemen..., hlm. 163 
Pada tahun 2014, genap satu tahun ada kunjungan dan monitoring dari OISCA Indonesia mengenai keberlanjutan dan kelayakan Children Forest Program di Pati. Dari hasil monitoring program bisa dilanjutkan dan OISCA Pati melakukan MOU dengan sekolah mitra sampai dengan lima tahun untuk setiap sekolah. Sebab respon baik dari pihak sekolah SDN Karaban dilanjutkan sebagai SDN mitra OISCA Pati sedangkan dengan SDN Tlogoayu tidak lagi berlanjut. Berdasarkan saran dari hasil monitoring yang dilakukan oleh OISCA Indonesia pada tahun 2014 OISCA Pati memperluas jaringan dan mendapatkan tambahan empat Sekolah dasar, yaitu SDN Tambah Harjo 02 Tambak Romo- Pati, SDN Jati Roto 04 Kayen-Pati, SDN Guwo 01 dan SDN Guwo 03 Tlogowungu Pati.

Kegiatan-kegiatan tersebut dilaksanakan di lima sekolah, pada tabel berikut ini akan peneliti jelaskan mengenai nama sekolah, tahun mulai program dan alamat sekolah peserta program CFP:

Tabel .1.1

Sekolah peserta program CFP di Kabupaten Pati19

\begin{tabular}{|c|c|c|c|}
\hline $\begin{array}{l}\text { 19 Laporan Semester } \\
\text { CFP, } 2016 \text { No }\end{array}$ & NamaSekolah & Mulai CFP (Tahun) & Alamat \\
\hline 1 & SDN 04 Karaban & 2013 & $\begin{array}{ll}\text { Jalan Pati }- & \text { Kayen } \\
\text { Km. } 10 & \text { Desa } \\
\text { Karaban, } & \text { Kec. } \\
\text { Gabus, Pati, Jawa } \\
\text { Tengah }\end{array}$ \\
\hline 2 & $\begin{array}{ll}\text { SDN } & 02 \\
\text { Tambaharjo } & \end{array}$ & 2014 & $\begin{array}{l}\text { Jl. Pati- Tayu Km.4, } \\
\text { Ds.Tambaharjo Rt. } \\
01 / \text { Rw. } 02 \\
\text { Kec.Pati, Kab.Pati, } \\
\text { Jawa Tengah }\end{array}$ \\
\hline 3 & SDN 04 Jatiroto & 2014 & $\begin{array}{l}\text { Desa Jatiroto, Kec. } \\
\text { Kayen, Kab. Pati, } \\
\text { Jawa Tengah }\end{array}$ \\
\hline 4 & SDN 01 Guwo & 2014 & Jalan Raya Pati- \\
\hline
\end{tabular}




\begin{tabular}{|l|l|l|l|}
\hline & & & $\begin{array}{l}\text { Gunungrowo Km } \\
12 \text { DesaGuwo, Kec. } \\
\text { Tlogowungu, Pati, } \\
\text { Jawa Tengah }\end{array}$ \\
\hline 5 & SDN 03 Guwo & 2014 & $\begin{array}{l}\text { Desa Guwo, Kec. } \\
\text { Tlogowungu, Pati, } \\
\text { Jawa Tengah }\end{array}$ \\
\hline
\end{tabular}

Laporan Semester CFP, 2016

Pelaksanaan program dimasing-masing SDN mitra NGO OISCA yaitu rutin dua kali dalam satu bulan, yang mana kegiatan ini disisipkan di jam pelajaran selama satu setengah jam untuk pendidikan lingkungan dalam bentuk Children Forest Program. Hari untuk kegiatan ini biasanya dipilih pada hari Selasa, Kamis, Jum'at dan Sabtu pada jam pelajaran ke-2 sampai ke-3. Hal ini berlangsung Satu tahun. Pada Tahun 2016 beberapa Sekolah sudah mulai membuka diri dengan menambahkan Children Forest Program sebagai ekstra kulikuler, dalam hal ini adalah SDN Karaban 04 dan SDN Tambah Harjo 02. ${ }^{19}$

Program ini dapat berjalan tidak lepas dari kegigihan Tim OISCA Pati yang saling suport satu dengan yang lainnya. Pada Tahun pertama kegiatan ini didampingi oleh Semua Tim Oisca Pati secara bergiliran, seiring berjalannya waktu yang mendampingi kegiatan ini adalah Staf Lapangan yaitu Agus, Anto kemudian kedua staf lapangan dapat panggilan magang di Jepang diambil alih oleh yuni dan susi. Berjalan sekitar satu tahun yuni mendapatkan panggilan dari salah satu TK diPati sebagai tenaga pendidik, yuni pun meninggalkan OISCA. Kemudian datang relawan (udin) untuk ikut serta mendampingi program bersama Susi. Pada pertengahan tahun 2015 tepatnya bulan Mei OISCA Pati membuka diri dengan menerima tujuh Mahasiswa IPMAFA.

Selain dari Staf lapangan OISCA Pati Peran Guru dan murid dalam pelaksanaan program ini sangat dibutuhkan sebab keterbatasan lembaga yang hanya dua kali dalam

\footnotetext{
${ }^{19}$ Observasi pada bulan November 2016 di SDN Tambah Harjo 02
} 
sebulan memberikan materi dan monitoring, untuk itu dalam keseharian yang mengawal program adalah pihak sekolah.

Kegiatan ini tidak akan bisa berjalan tanpa persiapan yang matang, setiap akhir bulan koordinator CFP bersama Staf-staf lapangan dan pengurus OISCA Pati mengadakan rapat bulanan dalam Fokus Grup Discusion yang membahas tentang pematangan rencana kegiatan bulan depan, mengevaluasi kegiatan yang telah berjalan dalam satu bulan dan membuat laporan bulanan yang nantinya akan dilaporkan kepada OISCA Indonesia dan Pihak sekolah Mitra NGO OISCA Pati. ${ }^{20}$

Komunikasi dan koordinasi secara verbal ataupun non verbal antara koordinator program dengan staf-staf lapangan, pengurus dan juga sekolah mitra terbangun cukup baik sehingga program ini berjalan cukup baik dan tergolong lancar dalam setiap pelaksanaannya. Children forest program ini menggunakan tanaman sebagai media pembelajarannya untuk itu sebelum kegiatan penanaman staf lapangan OISCA Pati melakukan survei lahan yang layak untuk ditanami terlebih dahulu dan dikoordinasikan dengan pihak sekolah dan koordinator program untuk menindak lanjuti bibit apa yang akan ditanam dilokasi. ${ }^{21}$

Selain itu setiap kali kegiatan siswa diberi intruksi oleh staf lapangan untuk menyiapkan bahan-bahan yang diperlukan untuk kegiatan yang akan datang, untuk menghindari hal-hal yang tidak diharapkan staf lapangan juga mengkoordinasikan dengan Kepala sekolah dan juga Guru pendamping guna mengingatkan siswa supaya tidak lupa pada saat hari pelaksanaannya. Pelaksanaan Childrens's Forest Program di NGO OISCA Pati sebagai berikut:

1. Persiapan penghijauan

2. Pelaksanaan Penghijauan

3. Pemeliharaan Tanaman

CFP Goodwill Ambassador adalah Program untuk mempresentasikan kegiatan CFP yang dilaksanakan selama Duta CFP mengikuti CFP disekolah. Yang bertujuan untuk belajar bersama dengan sekolah-sekolah CFP dinegeri lain. kegiatan ini di laksanakan di

\footnotetext{
${ }^{20}$ Observasi Pada 13 Desember 2016 di SDN Karaban 04 pukul 08.00-10.00 WIB.

${ }^{21}$ Observasi Pada 13 Desember 2016 di SDN Karaban 04 pukul 08.00-10.00 WIB.
} 
Jepang, yaitu di kota Tokyo dan Okinawa. Kegiatan CFP Goodwill Ambassador dilaksanakan selama 12 hari di Jepang, dari tanggal 16-27 November 2016. ${ }^{22}$

Pada kesempatan tahun ini, CFP OISCA Pati di tunjuk untuk dapat mewakili CFP Goodwill Ambassador dari Indonesia, yang akhirnya diwakili oleh siswa kelas VI dari SDN Karaban 04 yang bernama Rizki Rizal Fauzi. Selain 12 hari di Jepang, Duta CFP 2016 sebelumnya di karantina di OISCA Sukabumi Training Center (TC) selama 7 hari, kegiatan selama di OISCA Sukabumi TC adalah untuk melatih Duta CFP mempresentasikan kegiatan CFP di Indonesia menggunakan bahasa Jepang dan mengenalkan budaya daerah seperti pencak silat dan tarian yapong.

Selain mempersentasikan kebudayan dan kegiatan CFP OISCA di Indonesia para koordinator dan Duta CFP juga di perkenalkan budaya Jepang, keanekaragaman hayati, berinteraksi langsung dengan koordinator CFP dari negara negara lain. dan juga berbagi pengalaman tentang teknologi yang ada di Jepang, pengalaman berharga ini di harapkan dapat menambah semangat para siswa-siswi dalam melaksanakan kegiatan CFP di masingmasing sekolah, serta diharapkan mampu menarik motivasi untuk terus belajar mengenal dan mencitai lingkungan sekitarnya.

\section{b. Implikasi Childre's Forest Program}

Untuk mencapai tujuan, dalam pendidikan lingkungan hidup paling tidak memuat unsur-unsur pengembangan: (1) kesadaran dan kepekaan terhadap berbagai isu yang mengancam kelestarian lingkungan hidup. (2) pengetahuan dan pemahaman terhadap berbagai isu yang mengancam kelestarian lingkungan hidup. (3) sikap peduli terhadap lingkungan dan motivasi untuk meningkatkan dan menjaga kualitas lingkungan. (4) keterampilan untuk mengidentifikasi serta membantu untuk menyelesaikan berbagai ancaman lingkungan hidup dan (5) partisipasi dalam berbagai kegiatan yang dapat membantu menyelesaikan permasalahan yang mengancam kelestarian lingkungan hidup. ${ }^{23}$

Berdasarkan hasil penelitian, dengan menggunakan metode observasi, metode wawancara, dan metode dokumentasi. Maka peneliti menemukan beberapa pengaruh dalam

\footnotetext{
${ }^{22}$ Ajmala \& Arul, Laporan Tengah semester CFP Pati ,2016. Hlm. 6.

23 Abdul Karim, Manajemen Pendidikan Lingkungan Hidup Berbasis Partisipasi,(Yogyakarta :Pustaka
} Ifada, 2012), hlm.49. 
implementasi pendidikan karakter peduli lingkungan dalam Childre's Forest Program yang dilakukan OISCA Pati.

Children's Forest Program yang di rintis sejak 2013 oleh OISCA Pati dan masih berlangsung hingga hari ini berdampak positif bagi para siswa-siswa CFP dan lingkungan sekolah. Secara bertahap anak mulai sadar dan peduli tentang kebersihan lingkungan dan perawatan tanaman yang ditanam dilingkungan sekolah. Kebiasaan membuang sampah sembarangan disekitar sekolah sudah jarang terjadi semenjak Children's Forest Program masuk ke SDN Karaban 04. ${ }^{24}$ Begitu pun di SDN mitra OISCA Pati lainnya, sebab pada implementasi program terdapat kegiatan pemilahan sampah organik dan non organik serta pengertian tentang manfaat dan bahaya sampah yang diberikan kepada siswa dalam bentuk cerita dan juga pemutaran film di setiap SDN mitra OISCA Pati. ${ }^{25}$

Tanaman yang bertujuan untuk media pembelajaran siswa-siswa sekolah mitra OISCA Pati secara bertahap mampu memfasilitasi anak dalam proses pembelajaran yakni mulai dari penanaman tanaman, pemupukan, penyiangan, pembuatan ajir, menghitung daun, menyiram tanaman, pembuatan pupuk, pengenalan hama terhadap anak dan hingga buah dari tanaman yang ditanam oleh anak-anak bisa dinikmati.

Pelaksanaan program CFP ini dipublikasikan menggunakan media sosial yaitu Facebook oleh koordinator program untuk itu banyak khalayak yang tahu dan tertarik bertanya sekilas program. OISCA Pati beserta sekolah mitra secara tidak langsung disoroti oleh Sekolah dasar lain sebab Aksi-aksi Positif yang menanamkan kesadaran peduli lingkungan melalui Children's Forest Program. Dalam perjalanannya CFP OISCA Pati pada 2016 terpilih sebagai Duta CFP yang mewakili indonesia pada CFP Goodwill Ambassador di Jepang dan Okinawa. Untuk keberangkatan rizqi memerlukan surat pengantar dari daerah, maka CFP Goodwill Ambassador saat itu merupakan pintu masuk OISCA Pati dan KEMENDIKBUD Kabupaten Pati saling mengenal dan mendapat respon positif, yang

\footnotetext{
${ }^{24}$ Wawancara langsung dengan Yetti Nur Dwi Astuti, S.Pd selaku Kepala sekolah SDN Karaban 04 pada 3 Januari 2017 pukul 08.30-09.00 . di kantor SDN Karaban 04.

25 Hasil observasi langsung di SDN tambaharjo 02 pada kamis 5 Januari 2017, saat kegiatan presentasi dari Duta CFP dan pemutaran Film pada pukul 14.00-16.00 WIB.
} 
mana pihak Daerah Kabupaten Pati bangga disekolah dasar siswa-siswa di berikan pendidikan lingkungan. ${ }^{26}$

Perubahan perilaku dari anak CFP terlihat dari perilaku yang positif terhadap lingkungan dan mengurangi kebiasaan kecil yang merusak lingkungan yaitu anak CFP tidak melakukan:

1. Membuang sampah disembarang tempat

2. Corat-coret ditembok

3. Konsumsi plastik berlebihan

4. Mengabaikan pohon

5. Menganggap remeh daur ulang

Berdasar kajian teori dari Rian Sugiarto pendidikan karakter peduli lingkungan adalah usaha untuk menanamkan nilai-nilai karakter berbasis lingkungan yang berupaya meningkatkan kepekaan peserta didik terhadap pelestarian lingkungan. ${ }^{27}$

Sebagai tolok ukur keberhasilan Children's Forest Program di OISCA Pati maka setiap sekolah mampu menanamkan karakter peduli lingkungan. Ada beberapa indikator yang telah dicapai oleh sekolah dalam rangka menanamkan pendidikan karakter peduli lingkungan. Di antaranya:

a) Pembiasaan memelihara kebersihan dan kelestarian lingkungan sekolah

b) Tersedia tempat pembuangan sampah dan tempat cuci tangan

c) Menyediakan kamar mandi dan air bersih

d) Pembiasaaan hemat energi

e) Membuat biopori diarea sekolah

f) Membangun saluran pembuangan air limbah dengan baik

g) Melakukan pembiasaan memisahkan jenis sampah organik dan anorganik

h) Penugasab pembuatan kompos dari sampah organik

i) Menyediakan peralatan kebersihan

${ }^{26}$ Hasil Wawancara Dengan Totok Hadi Lukito, Koordinator Program CFP OISCA Pati, di Margorejo Pati pada 2 Desember 2016, 13.20- 14.20 WIB.

${ }^{27}$ Abdul Majid dan Dian Andayani, Pendidikan..., hlm .55. 
Selain indikator yang dicapai sekolah, dibutuhkan juga dukungan dari seluruh warga sekolah, orang tua dan warga sekitar sekolah untuk saling suport.Proses dalam mencapai indikator keberhasilan diatas pihak sekolah mitra OISCA Pati mempunyai hambatan yakni ketika anak sudah disiapkan untuk sadar kelestarian lingkungan akan tetapi di lingkungan sekolah setiap diluar jam sekolah halamannya di buat bermain anak kampung sepak bola, maka dari itu sedikit tanaman rusak oleh tangan-tangan jail.

Keresahan ini dirasakan hampir semua sekolah, sebab diluar jam sekolah tidak ada pengawasan khusus. Selain rusaknya tanaman oleh tangan jail anak-anak kampung, sejauh ini Tim Pelaksana CFP masih kesulitan dalam mengkoordinir anak-anak dilapangan. Sebab di masing-masing Sekolah tingkat keaktifan anak berbeda langkah yang diambil oleh Tim Pelaksana program yaitu dengan meminta guru pendamping untuk ikut terlibat dalam pengkondisian anak. Dan itu sangat membantu keberlangsungan program.

Dari pengamatan yang terlihat dilapangan idealnya pelaksanaan CFP tidak hanya dilaksanakan dua kali dalam satu bulan. Sebab menurut Thomas Lickona pendidikan karakter adalah pendidikan untuk membentuk kepribadian seseorang melalui pendidikan budi pekerti, yang hasilnya terlihat dalam tindakan seseorang. ${ }^{28}$ Karakter erat kaitannya dengan kebiasaan yang terus menerus dilakukan, setidaknya peneliti menyetujui apa yang Thomas kata kan dalam pendidikan karakter. Meskipun dalam prakteknya, secara sadar setiap hari para guru dan orang tua siswa terlibat dalam hal penanaman karakter peduli lingkungan yang merupakan buah dari kegiatan CFP yang berlangsung di Sekolah-sekolah mitra OISCA Pati. Dampak dari program ini terasa sekali terhadap guru, murid dan lingkungan sekolah, yang mana dari program ini digalakkan guru sadar dan mencontohkan aksi peduli lingkungan di sekolah. Sehingga murid melihat sikap guru yang demikian tergerak untuk peduli terhadap lingkungan sekolah yang akibatnya lingkungan sekolah tampak bersih dari sampah yang berserakan dan rindang sebab pohon-pohon yang terawat.

Children's Forest Program dalam perjalanannya di tahun ketiga berdasarkan pengamatan lapangan belum sepenuhnya berdampak pada karekter siswa, meskipun dalam teori Rian Sugiarto Pendidikan karakter Peduli lingkungan adalah usaha untuk

\footnotetext{
${ }^{28}$ Heri Gunawan, Pendidikan Karakter..., hlm.32.
} 
menanamkan nilai-nilai karakter berbasis lingkungan yang berupaya meningkatkan kepekaan peserta didik terhadap pelestarian lingkungan. ${ }^{29}$ Setidaknya peneliti menyetujui teori dari Rian Sugiarto, dari beberapa sekolah yang peneliti amati memang baru sekitar 25\% dari penanaman nilai-nilai karakter berbasis lingkungan yang diserap dan dipraktekkan oleh siswa-siswa CFP secara langsung. Sebab masih program ini masih dalam prosesnya, yang mana untuk mencapai ideal perlu inovasi, evaluasi dan juga dukungan dari pihak sekolah secara terus-menerus.

\section{Kesimpulan}

Bentuk kegiatan kongrit dari Children's Forest Program adalah melaksanakan kegiatan penyuluhan, nature game serta kegiatan yang mengarah kepada kecintaan anak-anak terhadap lingkungan. Penanaman/penghijauan pohon dilakukan sebagai media pembelajaran bagi siswa-siswa CFP. Program ini melibatkan lima sekolah dasar di kabupaten Pati, yakni : SDN Karaban 04, SDN Tambahharjo 02, SDN Jatiroto 04, SDN Guwo 01 dan SDN Guwo 03. Pelaksanaan program rutin dua kali dalam satu bulan di setiap sekolah CFP, yang diikuti oleh siswa-siswa kelas 3,4 dan 5 pada tiap sekolah. Dalam pelaksanaan kegiatan CFP didampingi oleh Tim lapangan OISCA CFP Pati. Beberapa kegiatan yang dilaksanan yakni : persiapan penghijauan, melaksanakan penghijauan, pemeliharaan tanaman. Adapun kegiatan pendukung dari pemeliharaan tanaman adalah pemupukan, penyulaman, penyiangan, penyiraman dan pemotongan cabang. Untuk pemilahan sampah, pembuatan biopori, pembuatan kerajian, kebersihan lingkungan merupakan kegiatan tambahan sebagai upaya dalam melaksanakan pendidikan lingkungan hidup, dan kegiatan tahunan yaitu pembuatan kartu ucapan sebagai kontribusi siswa CFP dalam pelaksanaan program.

29 Abdul Majid dan Dian Andayani, Pendidikan..., hlm.55. 


\section{Daftar Pustaka}

Ajmala \& Arul, 2016, Laporan Tengah semester CFP Pati

Astuti, Frismi, "Implementasi Program Adiwiyata Dalam Pengelolaan Lingkungan Sekolah dan Tingkat Partisipasi Warga Sekolah di SMP Kabupaten Wonosobo” Tahun 2015. vol. xix no. 2 (November 2014), http://journal.unnses.ac.id/sju/index.php/edugeo, di akses tanggal 21 Desember 2016.

Devisi CFP Pusat, 1993, Pedoman CFP Cildren's Forest Program

Hasil observasi langsung di SDN tambaharjo 02 pada kamis 5 Januari 2017, saat kegiatan presentasi dari Duta CFP dan pemutaran Film pada pukul 14.00-16.00 WIB.

Hasil Wawancara Dengan Totok Hadi Lukito, Koordinator Program CFP OISCA Pati, di Margorejo Pati pada 2 Desember 2016, 13.20-14.20 WIB.

Karim, Abdul, Manajemen Pendidikan Lingkungan Hidup Berbasis Partisipasi, Yogyakarta :Pustaka Ifada, 2012

Mattulada, 1994, Lingkungan Hidup Manusia, Jakarta: Pustaka Sinar Harapan

Milestones, http://www.oisca-international.org, diaskes tanggal 5 Januari 2017.

Mission, http:/ /www.oisca-international.org, diaskes tanggal 4 Januari 2017.

Observasi Pada 13 Desember 2016 di SDN Karaban 04 pukul 08.00-10.00 WIB.

Observasi pada bulan November 2016 di SDN Tambah Harjo 02

Panduan CFP

Pedoman CFP (cildren forest program)

Programs, http://www.oisca-international.org, diaskes tanggal 4 Januari 2017 .

Qaradhawi, Yusuf Al-, 2002, Islam Agama Ramah Lingkungan, Jakarta Timur: Pustaka AlKautsar

Santoso, Nyoto, "kebakaran butan gambut dan global warming, 2015", http://nasional.sindonews.com, diakses tanggal 21 Desember 2016.

Shihab, Quraisy, 2004, Tafsir Al-misbah, pesan, kesan dan keserasian Al-Qur'an, volume 5, Jakarta: Lentera hati

Sulikah, Siti dkk, 2015, Laporan Kelompok KKL 1 PMI IPMAFA di jaringan NGO OISCA Pati 
Tholhah dan Ahmad Mufid, 2008, Fiqih Ekologi: Menjaga Bumi Memahami Makna Kitab Suci, Yogyakarta: Total Media

Wawancara langsung dengan Yetti Nur Dwi Astuti, S.Pd selaku Kepala sekolah SDN Karaban 04 pada 3 Januari 2017 pukul 08.30-09.00 . di kantor SDN Karaban 04

Wawancara Langsung, Totok Hadi Lukito, Koordinator CFP OISCA PATI, di Margorejo Pati tanggal 2 Desember 2016, 13.20-14.20 WIB 